\title{
Corpo-outro: paradoxos da corporeidade na Contact Improvisation
}

Body-other: paradoxes of the body experience in Contact Improvisation

Pedro Rodrigo Penuela Sanches ${ }^{1}$ 


\section{Resumo}

Este trabalho pretende sintetizar algumas das principais discussões formuladas pelo autor em sua dissertação de mestrado, a respeito de diferentes atravessamentos entre corpo e alteridade, que emergem em experiências provocadas pela proposta de dança contemporânea denominada 'Improvisação em Contato' (ou 'Contato Improvisação'). Dialogando com conceitos oriundos da psicanálise e da filosofia, encontramos nessa forma de dança regimes complexos de relação, que variam de experiências de indiferenciação e comunicação imediata até experiências de confrontação e radical alteridade, não somente do corpo do outro, mas constitutiva do sujeito e da corporeidade.

Palavras-chave: Dança; corpo; corporeidade; Contato Improvisação; alteridade.

\section{Abstract}

Drawing on the results of the author's MA dissertation, this article reflects on different ways how the body is articulated with otherness through experiences provoked by a contemporary dance form called Contact Improvisation. Dialoguing with concepts from psychoanalysis and philosophy, complex regimes of relation can be found in this dance form, which range from indifferentiation and immediate communication to confrontation and radical otherness, not only in relation to the other's body, but constitutive of one's own self and corporeity.

Keywords: Dance; body; corporeity; Contact Improvisation; otherness. 
A vida e o corpo são no fundo a mesma coisa, mas para que eles efetivamente sejam a mesma coisa é preciso descobrir o corpo em sua força de gênese.

(Kuniichi Uno, 2010, p.44)

Atualmente, a teorização sobre a dança tem se desenvolvido como um campo de conhecimento sui generis, que não se confunde ou se pretende assimilado à discursividade específica de uma ou outra disciplina filosófica ou científica. No entanto, o diálogo com conceitos e discussões oriundos da filosofia e de diferentes ciências tem-se mostrado fecundo e potencializador da reflexão crítica sobre a dança, em especial quando tal diálogo parte do reconhecimento da diferença e das especificidades de cada campo, ao mesmo tempo em que ousa experiências "indisciplinares", de trânsito, contaminação, fecundação, atravessamento pela alteridade.

Nesse sentido, este artigo aposta no diálogo com a teoria psicanalítica, em especial a teoria construída pelo psicanalista inglês Donald W. Winnicott, como um espaço de reflexão sobre uma ambiguidade fundamental que caracteriza nossa experiência do corpo e que procuraremos resumir da seguinte maneira ${ }^{2}$ :

Do ponto de vista do senso comum e da experiência cotidiana, o corpo é nosso signo mais imediato de identidade e integridade. Reconhecemos nossa singularidade por sinais corporais como a impressão digital, a fisionomia, entre outros, que evidenciariam nossa existência como entes específicos, separados dos demais por uma fronteira material concreta e claramente delimitável. Por outro lado, é também no corpo que vivemos experiências de estranhamento e descentramento da identidade: a dor, o envelhecimento, as manifestações inconscientes (como os sintomas histéricos e psicossomáticos), assim como toda uma materialidade múltipla que a modernidade trabalhou arduamente para constituir como um objeto que nos é alheio, ainda que nos "pertença" e nos acompanhe, de maneira misteriosamente contígua a nossa subjetividade $^{3}$. Em outras palavras, o corpo parece atravessado por uma contradição intrínseca: se por um lado se confunde com o "cerne" do que somos, é também um campo de emergência de inúmeras experiências e realidades vividas como vindas de fora, de um alhures além da identidade, e é, ele próprio, concebido em nossa cultura como um objeto que possuímos e que podemos examinar e conhecer desde uma subjetividade conceituada como exterior a ele 4 .

Tal contradição ou ambivalência fundamenta grande parte do pensamento moderno e das práticas sobre corpo e sujeito (ou sobre o lugar ontológico do corpo), bem como atravessa radicalmente as práticas e usos do corpo na modernidade, entre elas a dança em especial.

Por outro lado, é também a dança um campo que, ao longo do século XX tem aberto espaço a experiências que reconfiguram a percepção e põem em questão as

\footnotetext{
${ }^{2}$ Outra formulação dessa ambiguidade, que nos influencia de partida pode ser encontrada em Merleau-Ponty, 1991.

${ }^{3}$ Para uma discussão sobre como a modernidade, em diferentes âmbitos, instaurou um projeto de objetificação do corpo, ao ponto de ele tornar-se naturalizado em nossa experiência cotidiana, cf. Sant'Anna, 1996 e LeBreton, 1999.

4 Refiro-me aqui ao pensamento de René Descartes especificamente, mas também à discursividade moderna sobre o corpo engendrada pelo Renasci-
} 
concepções do corpo consolidadas tanto no senso comum quanto no pensamento filosófico moderno (cf. Suquet, 2008; Gil, 2005). Nesse sentido, enfocaremos nesse trabalho algumas dessa experiências, tal como formuladas e propostas pela forma de dança denominada Contato Improvisação ${ }^{5}$, surgida a partir das pesquisas de Steve Paxton e outros bailarinos oriundos da chamada "dança pós-moderna" (cf. Banes, 1987 e 1983), nos EUA, nos anos 1970.

O contexto de surgimento da Improvisação em contato é marcado pelo trabalho de bailarinos (tais como o próprio Paxton, e também Simone Forti, Yvonne Rainer, Trisha Brown, David Gordon, Deborah Hay, entre outros) que radicalizaram a crítica aos dispositivos representacionais nas artes cênicas - crítica que desponta no trabalho de artistas da geração anterior, como Merce Cunningham, Erick Hawkins e Anna Halprin - desenvolvendo uma abordagem onde "o corpo em si mesmo tornou-se o assunto da dança, mais do que um instrumento de metáforas expressivas"6 (Banes, 1987, p. 18, intro.). A pesquisa sobre o corpo "em si mesmo" e seu deslocamento para fora da lógica representacional e dos dispositivos cênicos até então hegemônicos (incluindo o espaço teatral, o uso de figurinos, cenografia, etc.), levou a investigações ligadas à perda de controle, colisões, ao relaxamento e reconfiguração do tônus muscular, à inclusão de performers sem formação em dança, assim como à inclusão, em cena, de ações corporais cotidianas como caminhar, comer, dormir, etc. Esse mesmo campo de investigações implicava também uma maior politização dos trabalhos produzidos e a busca por formas de a dança acontecer para além da cena e da noção de coreografia - o que implicou na atribuição de um lugar fundamental à improvisação, assim como na valorização e incorporação de modos de pensar e fazer próprios das danças sociais, das artes do corpo de culturas não-ocidentais, do movimento dos animais, das ações rituais, e da arte da performance.

Tendo surgido como um dos desdobramentos desse contexto, a Improvisação em contato foi adquirindo certa estabilidade como proposta e forma de dança até tornar-se tanto um movimento artístico de grande alcance (a esse respeito, cf. Novack, 1990), como uma fonte de material técnico importante na formação de bailarinos em geral, dedicados especificamente a essa forma de dança, ou a outras abordagens da dança e das artes do corpo.

Ainda que seja uma proposta em certa medida refratária a definições peremptórias, pelo próprio caráter de experimentação e abertura que está em seu cerne, uma das maneiras de nomear suas intenções e características principais pode ser a seguinte, formulada pela dançarina Nancy Stark Smith:

\footnotetext{
5 "Contato improvisação" tem sido a tradução mais utilizada pelos dançarinos no Brasil para a expressão original Contact Improvisation. No entanto expressões como "improvisação de contato", ou "improvisação em contato" seriam mais precisas e mais adequadamente correspondentes à gramática do idioma inglês, de modo que optamos por utilizar "Improvisação em contato" em quase todo o texto, com exceção dos casos em que é mantida a expressão no idioma original, ou quando se pretende evocar indiretamente a apropriação brasileira
}

dessa forma de dança ou sua constituição como um movimento artístico. Também é usada no texto a sigla "Cl", como abreviação de Contact Improvisation, tal como ocorre na bibliografia em inglês.

6 "The body itself became the subject of the dance, rather than serving as an instrument for expressive metaphors." (Tradução livre feita pelo autor). 
O Contact pode ser visto como um meio de comunicar-se através do contato físico. O diálogo acontece pelo uso da troca de peso entre os parceiros para sintonizá-los com as forças físicas que efetuam seu movimento e para sintonizá-los um com o outro. No começo da improvisação em contato, uma escolha foi feita por minimizar o conteúdo social do contato e por trabalhar, inicialmente, com os elementos físicos envolvidos na troca. Declarada ou implicada pelo exemplo, essa escolha, junto a outras, trouxe profundidade à prática do Contact por limitar seu escopo. Estreitando o foco da atividade, a informação sutil tornou-se visível: a experiência da gravidade; a "pequena dança" do esqueleto balançando ereto; o fluxo do peso através do corpo enquanto ele rola pelo chão; a troca de peso entre parceiros durante levantamentos, carregamentos, e lançamentos; a sensação de compartilhar um centro de equilíbrio dinâmico com outro movente (Smith, 1979/1997, p. 49)7.

Do ponto de vista de sua relevância para a história da dança, a historiadora Annie Suquet coloca que:

A contact improvisation [...] sintetiza muitos dos desafios da dança contemporânea. E ao mesmo tempo constitui para ela um ponto limite. A forma, a estrutura aí são radicalmente subordinadas ao processo. A contact improvisation permite que se veja a emergência do movimento: é a experiência que cria um espetáculo, aquém e além de toda representação mental. [...] Através da exploração do corpo como matéria sensível e pensante, a dança do século XX não cessou de deslocar e confundir as fronteiras entre o consciente e o inconsciente, o 'eu' e o outro, o interior e o exterior. [...] Ao longo do século, a dança contribuiu para desafiar a noção de 'corpo', a tal ponto se tornou difícil ver no corpo dançante essa entidade fechada em que a identidade encontraria seus contornos (Suquet, 2008, p. 537-538).

Tendo em vista o que coloca Suquet, uma das implicações fundamentais das investigações da dança ao longo do século XX e mais radicalmente, daquelas provocadas e produzidas pela improvisação em contato é a emergência de uma corporeidade que, além de romper de diferentes maneiras com um complexo processo de docilização e objetificação do corpo ao longo da modernidade ${ }^{8}$, também impossibilita que o corpo siga sendo conceitualmente abordado segundo as necessidades de uma filosofia da identidade, quer dizer, que ele siga sendo um signo ou evidência de identidade, na medida em que se revela, na dança, aberto e intrinsecamente inacabado, espaço de emergência de alteridades e modos de ser (ou vir-a-ser, devires) inestáveis e insólitos - nas palavras de Kuniichi Uno, "inapreensível, inesgotável, irredutível. [...] O corpo é esse estranho começo e recomeço que pode colocar tudo em questão" (Uno, 2010, p. 37). 7 "Contact can be seen as a means for communication through physical con-
tact. Dialogue proceeds, using the exchange of weight between partners to
tune them to the physical forces that effect their motion and to tune them to
each other. At the outset of Contact Improvisation, a choice was made to mi-
nimize the social content of the contact and to work, initially, with the physical
elements involved in the exchange. Stated or by example implied, this choice
along with others brought depth to the practice of Contact by limiting its scope.
By narrowing the focus of the activity, subtle information was made visible: the
experience of gravity; the 'small dance' of the skeleton balancing erect; the flow of weight through the body as it rolls across the floor; the exchange of weight between partners during lifting, throwing and catching; the sensation of sharing a dynamic center of balance with another mover." (Tradução livre feita pelo autor)

8 Para uma discussão mais detalhada a respeito da noção de corpos dóceis e das maneiras objetificantes e alienantes de abordar o corpo na modernidade, remeto o leitor a Foucault (1975/2009), Le Breton (2003), e especificamente com relação às implicações na dança deste processo histórico, cf. Launay (2003). 
Por caminhos diversos e paralelos ao desenvolvimento da dança no século XX, a psicanálise igualmente engendrou uma prática (a clínica psicanalítica) e um campo de teorização que dão testemunho e, paulatinamente, conceituam um corpo radicalmente distinto do corpo-objeto identitário cunhado pela filosofia moderna9.

No caminho desse desenvolvimento conceitual, Donald Winnicott, um autor pouco conhecido fora do campo psicanalítico, é, no entanto, de especial importância para uma reflexão contemporânea sobre a corporeidade e para possíveis diálogos entre a dança e a teoria psicanalítica, na medida em que fundamenta sua teorização em uma abordagem centrada no corpo, sobretudo a partir de observações de experiências vividas na relação mãe-bebê, em épocas muito iniciais do desenvolvimento.

Ao atentar-se às experiências mais "primitivas" de constituição do sujeito (basicamente corporais e não-verbais), Winnicott dá lugar, em sua trama conceitual, a uma modalidade de relação entre o bebê e a mãe em que esta ocupa um papel de "mãe -ambiente", cujo cuidado e responsividade corporal às necessidades e à singularidade do bebê constituem um espaço potencial, que permite ao bebê aos poucos articular as experiências corporais, por meio do que Winnicott chama de "elaboração imaginativa". Como explica Elsa Dias a esse respeito:

O funcionamento psíquico inicial é [...] relativo ao soma, pois seja o que for que esteja sendo experienciado pelo bebê, tudo é experienciado no corpo ou através dele e está sendo personalizado pela elaboração imaginativa. Esta, diz o autor, "é uma forma rudimentar do que mais tarde chamaremos de imaginação" (1993/1993, p. 21). Não se trata, ainda, da fantasia do corpo que virá depois, pois esta é eminentemente representacional e depende de um funcionamento mental que ainda não foi ativado nesse momento inicial. A elaboração imaginativa é, bem mais, o que provê de sentido ao que seria, de uma perspectiva puramente organicista, uma mera sensação; do ponto de vista da experiência humana, contudo, há sempre um sentido, mesmo que altamente incipiente, tal como estar protegido ou não, sentir-se ou não seguro, deixar-se ir ou ser interrompido, sentir urgência, sentir-se solto no vazio, ter algo entrando, ter contato ou não, etc. (Dias, 2007).

Sendo assim, Winnicott constrói uma teorização das relações entre corpo e psique ou corpo e subjetividade não mais fundamentada no paradigma cartesiano da representação (o sujeito como sinônimo de uma res cogitans ontologicamente separada da materialidade do corpo, à qual somente acessa por meio de "representações mentais"), mas sobretudo fundada em uma atenção clínica às experiências corporais fundamentais do início do desenvolvimento e à concretude corpórea dos processos de constituição de um "psique-soma", um corpo subjetivado, elaborado imaginativamente e vivido por um sujeito como um "continuar a ser".

O estabelecimento desta corporeidade ao mesmo tempo depende e é condição da possibilidade de brincar - modalidade de relação com o mundo que, em Winnicott, constitui um paradigma de toda possibilidade de apropriação da cultura por parte de

\footnotetext{
9 Há uma vasta bibliografia discutindo o lugar corpo na teoria psicanalítica. Dentre os vários trabalhos a esse respeito, remeto o leitor a Fernandes (2003), Dejours (1986) e Safra (2005).
} 
um sujeito e de uma vida sentida como "valendo a pena ser vivida":

É no brincar, e somente no brincar, que o indivíduo, criança ou adulto, pode ser criativo e utilizar sua personalidade integral: e é somente sendo criativo que o indivíduo descobre o eu (self). (...) $\mathrm{O}$ eu (self) realmente não pode ser encontrado no que é construído com produtos do corpo ou da mente, por valiosas que essas construções possam ser em termos de beleza, perícia e impacto (Winnicott, 1975, p. 80-81).

O brincar estabelece uma relação com a realidade baseada na experiência paradoxal de sentir a realidade como tendo sido criada por si, e ao mesmo tempo poder reconhecê-la como precedente a si mesmo - experiência que Winnicott pôde abordar com clareza a partir da atenção ao que ele chamou de fenômenos transicionais, que aparecem, por exemplo, quando a criança escolhe determinados objetos da realidade externa como objetos transicionais, isto é, que lhe permitem fazer o trânsito entre realidade interna e externa, na medida em que são vividos como sendo parte, paradoxalmente, de ambos os mundos. É essa experiência transicional, que caracteriza o brincar, que permitirá ao sujeito partilhar do campo da cultura, tal como explica Rogério Luz:

O que Winnicott pretende tematizar é o vazio virtual que une, ou separa, o mundo da cultura e o sujeito, para descrever a singular atividade psíquica que ali se inaugura. [...] O jogo 10 é, ao mesmo tempo, gestualidade inscrita na materialidade do que o mundo pode apresentar ou oferecer e simbolização do que nele se ausenta. [...] O jogo, [...] permite a comunicação e a circulação da experiência sob a forma primeira do paradoxo vivido. Espaço de contínua passagem entre não-ser e ser, o mesmo e o outro, repouso e movimento (Luz, 1998, p. 166-167).

Essa teorização sobre o brincar como uma espécie de paradigma das relações entre o sujeito e o mundo pode ter uma potência significativa para pensarmos as experiências de contato e diálogo entre corpos, na medida em que estabelece uma possibilidade de pensar a relação eu-outro (assim como as relações eu-corpo, corpo própriocorpo do outro ou ainda corpo-atual e corpo-da-memória, corpo-real e corpo-virtual, entre outras modalidades de dualização e desdobramento da corporeidade) sob um ponto de vista paradoxal, diferente de um dualismo ontológico inconciliável (como na filosofia moderna) ${ }^{11}$.

Dito isso, detenhamo-nos então na discussão sobre as experiências de contato e relação propiciadas pela improvisação de contato, a fim de pensar em que medida este paradigma do brincar, juntamente com os demais conceitos winnicottianos correlatos, nos permitem elucidar modos de relação constitutivos do corpo que nos levem a elucidar a questão norteadora básica que formulamos no princípio deste texto.

\section{Contato}

Pela importância que dá ao toque e contato físico, a Improvisação de contato foi se tornando cada vez mais uma pesquisa sobre possibilidades de comunicação não

\footnotetext{
${ }^{10} \mathrm{O}$ autor utiliza a palavra jogo como sinônimo de "brincar", termo que estamos utilizando aqui. Ambas são traduções possíveis para a palavra playing, utilizada por Winnicott.
}

${ }_{11}$ Para uma discussão mais ampla sobre as relações entre o conceito Winnicottiano de "brincar" e a improvisação em dança, remeto o leitor a Dissertação do autor (citação suprimida para evitar identificação de autoria) 
limitada à linguagem verbal. Quer dizer: quando é posto em suspenso o principal código comum de signos de referência que temos para nos comunicarmos (a linguagem verbal), como se estabelece a comunicação? Que tipo de experiência de comunicação é essa que acontece entre os dois dançantes, quando parecem dialogar corporalmente, sem palavras?

Uma resposta possível é o reconhecimento de que, na improvisação de contato, por conta, entre outros fatores, da velocidade e complexidade da movimentação que se produz entre os corpos, acaba por estabelecer-se um tipo de interação em que os dois corpos agem como se fossem parte de um único corpo - o que implicaria em uma comunicação imediata.

Como coloca Steve Paxton:

A experiência é inteiramente pessoal no que se refere ao tato. Comporta as impressões sensoriais, e os sentimentos sobre essas impressões. [...] É a experiência, e depois a experiência dessa experiência. [...] No entanto, se dois espíritos estão centrados no mesmo fenômeno (tato, música, palavras), acontece alguma coisa que se assemelha muito a uma experiência recíproca (mutuality of experience). É como ter acesso a outro espírito. Não ler o pensamento de outrem, como imaginamos, porque não sabemos o que esse espírito sente: [sabemos] apenas que é um sentir, centrado no tato comum, que tem lugar. [...] Neste tipo de reciprocidade, a velocidade de transmissão e retransmissão é suficientemente rápida para se inscrever na nossa intenção e estimular os nossos reflexos. O que afeta o curso da dança sem uma decisão consciente da nossa parte (Paxton, citado por Gil, 2005, p. 111-112).

O filósofo José Gil, ao refletir sobre esse tipo de experiência, a compreende como o estabelecimento de um tipo de comunicação inconsciente, em que se estabelece um saber tácito sobre o outro, um saber que não passa pela consciência-pensamento, mas que acontece em fluxo. Em suas palavras:

É a consciência do corpo que abre o corpo do bailarino ao do seu par; e é a comuni-
cação inconsciente do movimento (por osmose) que permite a criação de um fluxo
único que atravessa os dois corpos ligando-os tão estreitamente que agem com a es-
pontaneidade, a fluência, a lógica rigorosa dos gestos de um só corpo (quando cada
um deles improvisa). [...] Porque os movimentos de um bailarino vão ao mesmo
tempo comandar e obedecer aos movimentos do outro bailarino; cada um antecipa
e adivinha os movimentos do outro como se fossem os seus próprios movimentos,
como se os movimentos do outro se desenrolassem segundo a carta dos seus movi-
mentos atuais (Gil, op. cit., p. 116 e 117).

Gil, procura explicar qual seria o meio de comunicação que fundamenta esse tipo de relação indiferenciada com o outro, recorrendo à noção de atmosfera - que não se confunde com um contexto, com um ambiente, mas que "faz parte dos corpos" de maneira "infra-semiótica", "interior-exterior" (Gil, op. cit., p. 119-121).

A comunicação pelas atmosferas seria uma modalidade de produção de sentido sem recurso a representações (e possivelmente a qualquer outra forma simbólica). Estabelecida a atmosfera, ela pode adquirir textura, viscosidade, densidade. Gil dá o exemplo de um casal que se solidifica num tipo de simbiose em que a atmosfera se torna de tal modo densa que a comunicação entre os dois é praticamente imediata, e os gestos tendem à previsibilidade e à repetição.

Levando em conta essa dimensão, cabe lembrar, como coloca a dançarina Nita 
Little $^{12}$, que o contato começa muito antes do toque da pele, com um "feixe intencional" do corpo para o espaço, que permite a quem dança sentir o corpo do outro, as texturas de uma parede, a entrada da luz, etc. mesmo de longe. O contato começa já na própria transformação do espaço em corpo-espaço (o espaço se densifica, o corpo ganha como que linhas invisíveis que o ligam a tudo ao redor), num processo em que as relações ganham uma permeabilidade própria (cf. Gil, op. cit., p. 50).

De fato, em grande medida os duos de $\mathrm{Cl}$ acontecem assim, com o estabelecimento dessa permeabilidade, desse "corpo único" que articula intimamente os dois dançarinos.

Mas, o modelo da "simbiose", isto é, do corpo único que permite a um dançarino "adivinhar" o movimento do outro, não abrange toda a experiência propiciada pela $\mathrm{Cl}$, já que, além da adaptabilidade e da comunicação aparentemente imediata e inequívoca, é parte fundamental da proposta, para que ela possa ser afinal uma improvisação, que o outro seja uma fonte de imprevisibilidade, que o outro seja uma alteridade, ou seja, o outro é sempre outro e seus gestos são sempre em algum grau imprevisíveis (mesmo que isso possa ser minimizado em algumas situações). Sendo assim, outras modalidades de relação com a alteridade (aquelas não necessariamente ligadas à indiferenciação e ao saber compartilhado), diferentes da simbiose ou da indiferenciação, são igualmente fundamentais nas experiências provocadas pela Improvisação em contato.

\section{Alteridade}

No processo de pesquisa que resultou na dissertação de mestrado da qual este artigo é um desdobramento, foram coletados relatos de participantes de "oficinas de Contato Improvisação" propostas pelo pesquisador ${ }^{13}$. Nesses relatos, são narradas experiências de encontro com o outro que variam entre a indiferenciação, própria do engendramento de uma espécie de "terceiro corpo", que unificaria os dançarinos em contato (tal como discutido acima); passando por experiências de contato com um outro semelhante mas não indiferenciado - quando o contato com o outro, por sua diferença, presentifica o corpo do sujeito, na medida em que estimula concretamente a sensação de determinadas partes ou modos de ser do corpo, inacessíveis antes do contato, ou ainda; por experiências de estranhamento, em que o contato com o outro é vivido como desconfortável, doloroso, remetendo o sujeito à sensação de intrusão ou choque.

No entanto, o que articula os diferentes relatos de experiências com a $\mathrm{Cl}$ é a experiência do corpo como aberto e inacabado e a surpresa de encontrar-se com facetas de si antes não acessíveis (isto é, com os outros em si mesmo). Quer dizer, a presença do outro nos permite acessar nossa própria alteridade constitutiva. O confronto, a descoberta, o compartilhamento ou o choque, a experiência consonante ou dissonante da diferença do outro, permite que nos reencontremos com nossa própria diferença

${ }^{12}$ Em um workshop dado no $3^{\circ}$ Encontro Internacional de Contato Improvisação de São Paulo, em 2011.
${ }^{13} \mathrm{Cf}$. Dissertação do autor (citação suprimida para evitar identificação de autoria) 
intrínseca e também com nossa singularidade.

Sobre esse ponto, há um belo texto de Nancy Stark Smith em que ela conta a experiência de ter se surpreendido fazendo um movimento que ela não reconhecia como seu próprio, e que na verdade era um movimento de Lisa Nelson (dançarina com quem trabalhava) - um movimento com uma qualidade típica da movimentação de Lisa. A partir disso, ela começa a descobrir qual é qualidade, os tons, etc. característicos da sua movimentação:

'Fazendo a Lisa', eu fui em seguida surpreendida pelo fato de que apesar de estes serem movimentos que eu podia fisicamente fazer, eles não eram os que eu comumente escolheria. Eu tinha até então suposto que ao improvisar, eu estava convocando qualquer movimento que eu pudesse fazer, mas agora eu percebi que eu estava de fato usando um repertório muito limitado e consistente de movimentos, texturas e tempos. Que eu estava, de fato, sempre, 'fazendo eu mesma'. Eu achei isso uma descoberta bastante reveladora e um exercício de humildade ${ }^{14}$ (Smith, 1986/1997, p. 105).

Como fica claro pela experiência de Smith, constitui-se uma corporeidade pelo encontro com o outro - o acesso e o reconhecimento da singularidade corpóreosensorial do outro (às vezes surpreendentemente incorporada em nós), nos oferece de maneira palpável a nossa própria singularidade corporal e subjetiva. ${ }^{1}$

A coexistência, no encontro com o outro, das dimensões da semelhança e da diferença gera um trânsito entre a experiência de reconhecer uma singularidade própria (manifesta em certa gestualidade específica, em certa forma do corpo, certa sensorialidade privilegiada, certo "estilo de ser") e a experiência de surpreender-se aberto, permeável, desconhecido.

\section{Incorporação}

Um outro aspecto, igualmente fundamental, dessa permeabilidade e dessa constituição alteritária do corpo refere-se às relações entre o corpo e a matéria não -humana do mundo e das coisas, bem como entre o corpo já elaborado imaginativamente e outras sensações do corpo insuspeitas ou rememoradas, que o aproximam sensorialmente da matéria das coisas, e, de início, o fazem ser sentido como um corpo estranho ou um corpo mais complexo do que aquele que se mostra no cotidiano.

Nos relatos dos participantes da pesquisa citada, aparecem claramente (pelo menos) dois tipos de experiências diretamente ligadas a esse tema, quais sejam: 1. a experiência dos desdobramentos e transformações, no corpo, ocasionados pelo contato com imagens vindas "de fora", tais como as imagens usadas nas propostas das oficinas (do tipo rolar "como uma bexiga d'água" ou "sentir a água do corpo ir toda para o chão", etc.) e, 2. a emergência de imagens que os participantes encontraram espontaneamen-

14 "In 'doing Lisa' I was further struck by the fact that although these were all movements I could physically do, they were not ones I would ordinarily choose. I had been under the assumption that in improvising I was calling on any and every moment I could possibly make, but now I realized I was in fact doing a

very limited and consistent range of movements, textures and timings. That I was, in fact always 'doing myself'. I found this a rather humbling and revealing discovery." (Tradução livre feita pelo autor). 
te, quase sempre ligadas a alguma experiência pessoal singular evocada pelo corpo rememorada por meio de determinada movimentação, ou sensação.

À primeira vista, esses dois tipos de relações entre corpo e imagem parecem ter muito pouco a ver um com o outro. No entanto, pretendemos mostrar, a partir do diálogo com Winnicott (e com uma idéia de Walter Benjamin), que há uma articulação importante entre eles.

Em primeiro lugar, com relação às imagens rememoradas a partir de movimentos corporais, temos relatos como os seguintes:

[...] O chão, ficar na horizontal, em contato com o solo é uma sensação boa, de firmeza.

Deslizar no chão também. Parece que memórias antigas de bebê vêm à tona. (M. I. M., 20/08)

[...] No rolar lembranças da infância me vieram a mente, e recordei do cheiro da terra e do mato da pequena cidade em que nasci. Os movimentos do corpo proporcionaram uma deliciosa viagem a minha mente (M. 20/08).

Em ambos, diferentes tipos de movimentação (em um caso o repouso no chão e o deslizamento, e em outro caso o rolamento) despertam, evocam a memória de certas experiências vividas, nos dois os casos, na infância. Ou seja, temos aqui exemplos do que, em diferentes contextos, se costuma chamar de "memória corporal", isto é, o fato de que as experiências que vivemos estão, de algum modo, "armazenadas" em nosso corpo.

Um conceito de Winnicott que nos permite traçar uma compreensão desse tipo de experiência é o conceito de "incorporação" (embodyment). Trata-se de um conceito que Winnicott desenvolveu a fim de descrever uma experiência fundamental e primária no processo de constituição do psicosoma, distinta do processo de "introjeção", tematizado pela teoria da psicanalista Melanie Klein. Como explicam Alfredo Naffah Neto e Elsa Dias:

Winnicott distingue incorporação de introjeção. Incorporar bons objetos sob a forma de cuidados, nessa distinção, é um processo espontâneo que ocorre desde o início, como forma natural de crescimento, sem nenhuma conotação defensiva. [...] Já introjetar 'bons objetos' implica uma idealização mágica dos objetos internalizados, na linha de um mecanismo de defesa contra a angústia, quando o ambiente torna-se ameaçador (Naffah Neto, 2012, p. 8).

A distinção entre incorporação e introjeção foi formulada por Winnicott à luz do amadurecimento e em termos da natureza dos processos: a incorporação tem início nos estados mais primitivos, não envolve nenhum trabalho mental e ocorre durante as experiências instintuais excitadas. Mais: o que é incorporado não é um objeto, nem a fantasia do objeto, mas a experiência de cuidado ambiental, com a respectiva conjunção psicossomática envolvida [...] (Dias, 2007).

Ou seja, a incorporação é um conceito que procura apontar a maneira como, num processo bastante gradual e lento, o bebê vai constituindo o corpo, sedimentando a continuidade de experiências sensoriais, ligadas inicialmente ao cuidado materno. 
Ainda nas palavras de Elsa Dias:

Alguns exemplos de incorporação, do início e ao longo da vida, podem esclarecer. 1. O bebê faz o gesto de tentar alcançar algo, um chocalho, por exemplo. A mãe percebe o movimento e implementa o gesto: alavanca o corpo do bebê, faz com que sua mãozinha chegue ao objeto e ele agarra o objeto. A possibilidade de alcançar objetos, juntamente com a força e a direção imprimida ao movimento, juntamente com a possibilidade de comunicar o objetivo, tudo está sendo incorporado de modo a tornar-se uma potência e uma habilidade do próprio bebê, o que leva, naturalmente, com o tempo, a uma crescente organização psicossomática. Além disso, a experiência, que envolve a pessoa total do bebê, teve começo, meio e fim, o que implica incorporação do tempo das coisas, dos acontecimentos e, inclusive, do cansaço psicossomático (Dias, 2007).

Os exemplos dados por Dias, com a licença da longa citação, esclarecem a amplitude desse conceito e o fato de que, mesmo que ele tenha se construído a partir de um pensamento sobre experiências muito iniciais na vida de um bebê, ele também elucida experiências que acompanham toda a vida de uma pessoa.

De nosso ponto de vista, trata-se de um conceito que condensa de certo modo o que estamos discutindo até aqui, já que nomeia o processo de constituição alteritária do corpo. Ou seja, o que Winnicott, de acordo com Dias, está apontando é que o próprio corpo se torna um corpo vivo e subjetivado (diferente de uma representação mental de corpo), porque vive experiências com outro corpo vivo - sendo que a maneira como este outro corpo se faz presente em cada momento, isto é, seu estilo singular (ou "idioma pessoal", na expressão de Gilberto Safra) de fazer cada gesto e toda a sensorialidade específica que este estilo compõe, é veiculadora de sentido.

Portanto, em primeiro lugar, o conceito de incorporação nos ajuda a compreender o que costuma ser chamado de "memória corporal", não como um fenômeno apenas de associação entre representações (uma "representação mnêmica" de uma experiência associada cerebralmente à representação de certa sensação ou movimento corporal que lhe foi concomitante), mas como a evidência de que o corpo se constitui materialmente a partir das experiências vividas com o outro e com o mundo.

Em outras palavras, não há um corpo anterior ao encontro com outros corpos, que colocaria para dentro de si elementos da experiência com estes. O próprio corpo acontece na medida em que "incorpora" a presença continuada do corpo personalizado, vivo, do outro - que se manifesta inicialmente na concretude do cuidado materno.

Portanto, a incorporação, na leitura que queremos sustentar, não se refere apenas a um processo eminentemente psíquico ou neuronal, de sedimentação de memórias de experiências que de início foram corporais, mas que passam a ocupar a vida ulterior como representações psíquicas, imagens, conexões sinápticas, etc.

$\mathrm{Na}$ incorporação inicial, o continuar a ser de toda a sensorialidade dos cuidados recebidos pelo bebê, ou, em outras palavras, a sensorialidade do encontro entre o corpo do bebê e o corpo da mãe (ou cuidador), constitui o corpo do bebê em toda sua materialidade, na medida em que dá presença e existência a certas partes do corpo, assim como a certos modos de esse corpo acontecer (variações e possibilidades de variação do tônus muscular, possibilidades de crescimento, formação de tecidos, 
etc.).

Algo que nos parece uma evidência dessa materialidade da incorporação é a maneira como o corpo é permeável - no sentido de modificar-se em seu tônus, na organização do peso, no estado de relaxamento, ou seja, em sua materialidade - a certas imagens que evocam qualidades sensoriais dos objetos (animados ou não). Um número significativo de relatos coletados em pesquisa faz referência a essa permeabilidade. Destacamos dois:

[...] Achei bem interessante, pensar no saquinho d'água, pois quando pensamos em água, pensamos em fluidez, e parece que os movimentos ficam mais contínuos e o corpo fica também mais fluido (A. C., 30/07).

[...] A idéia de abraçar, sentir o corpo com o outro sugerindo qualidades faz o movimento tornar-se mais distante do pensamento. O toque da voz daquele que guia é recebido pelo corpo como um norte, um caminho possível. É claro que a imagem vem mas logo ela se dissolve nas mãos, braços, pernas, cabeça, tronco e gera um movimento da representação da qualidade. Não reproduzimos a qualidade em si, mas o que a mesma provoca em nosso corpo. Essa experimentação provoca uma sensação libertária, no sentido de não mais prender gestos, sons. Faz sentir e criar, um criar leve, solto (M., 12/11).

Ambos os relatos são bastante precisos ao se referir à experiência de que o corpo se modifica materialmente, quando é evocada certa qualidade sensorial.

Considero que o fato de o corpo se transformar quase que imediatamente diante da sensorialidade evocada por esse imagens como as citadas nos relatos é uma evidência de que nossos corpos estão constantemente em processo de incorporação, quer dizer, estão sempre registrando sensorialmente, na sua materialidade, as mais diversas e complexas qualidades sensoriais dos objetos com os quais se relacionam. Por isso que é tão possível produzir certa fluidez de movimentos com a imagem da água, ou certa abertura de espaço nas articulações com a imagem do azeite entre elas, etc.

Uma observação que talvez ajude a esclarecer esse campo é a de Walter Benjamin (1933), que defende a existência de um tipo de uma "faculdade mimética", que seria própria da condição humana e subjacente a toda linguagem, como uma forma de associar imediatamente inúmeros fenômenos, encontrando possibilidades de mútua influência e produção de novos sentidos pelo encontro de semelhanças - capacidade que Benjamin observa ser especialmente presente na brincadeira das crianças, que "imitam" tanto as pessoas ao seu redor, como os objetos.

Quer dizer, a proposta baseada na imagem de transformar o corpo em uma gelatina, por exemplo, pode modificar toda a tonicidade dos músculos, a qualidade da respiração e dos gestos, porque corpo e mundo se comunicam diretamente nesse campo experiencial em que a moleza-firme da gelatina imediatamente evoca outras molezas-firmes independentemente da criação de um conceito abstrato de moleza que unificaria as experiências concretas da moleza.

Nesse sentido, o processo de incorporação - de constituição do corpo na experiência com o outro - não seria apenas um processo atuante na vida inicial do bebê, ou em certas situações específicas, mas está sempre presente em algum grau 
e ligado a todos os contatos sensíveis que estabelecemos com o mundo.

Reconhecer isso adiciona um elemento a mais para sustentarmos a importância de experiências táteis complexas, como as propiciadas pelo $\mathrm{Cl}$, na medida em que estas abrem possibilidades de constituição e re-constituição de si, ou ainda, se quisermos, de criação, de brincadeira com o próprio corpo e com o mundo.

\section{À guisa de conclusão: a alteridade constitutiva do corpo}

Como nos lembra Christine Greiner, na própria origem etimológica da palavra "corpo" radica a:

Necessidade de estabilizar algo em torno de um objeto para que este represente o que resiste ao que poderia ser desfeito - a solidez como uma espécie de solidariedade entre seus componentes, a coerência, a coesão e figurabilidade ou a face própria para cada entendimento de corpo (Greiner, 2005, p. 17).

Com relação à tentativa de fixação, entificação, ou objetificação do corpo e do sujeito, a psicanálise tem trazido desde Freud posicionamentos bastante subversivos, na medida em que começa por mostrar que a experiência de estranhamento e descentramento da identidade não é exclusiva das relações entre sujeito e corpo, mas é traço fundamental da relação da própria subjetividade. A aventura psicanalítica tem sido desde o início - se não totalmente, ao menos em sua tendência mais fecunda - a aventura do descentramento do sujeito, isto é, do reconhecimento do estranhofamiliar (Freud, 1919), do estranho que somos para nós mesmos.

Assim, desde o início, a psicanálise apontará que a subjetividade não configura uma totalidade fechada e coesa, de modo que não há precisamente um sujeito fixo, único e constante que poderia então contemplar seu corpo como um objeto precário no qual apoia materialmente sua existência pensante.

O estranhamento que porventura sentimos com o som de nossas vísceras, a radical divisão subjetiva provocada por uma mínima dor de dente, o descompasso entre nosso corpo "real" e nosso desejo sobre o corpo, ou nossas obrigações, ou nossos ideais ou a imagem inconsciente do corpo, ou o esquema corporal, enfim, os inúmeros descompassos entre corpo e sujeito não são menores nem de natureza diversa dos descompassos entre o sujeito e ele mesmo, e entre o corpo e ele mesmo. Nossos sonhos, atos falhos, nossa imagem em um espelho quando produzida inesperadamente, nossos gestos em um vídeo, certas narrativas que contam a nosso respeito, o personagem que somos para distintas pessoas em distintos grupos separados com os quais convivemos são tão estranhos-familiares quanto são para nós as batidas de nosso coração, os movimentos das vísceras, etc. Como são igualmente estranhos e familiares, ao mesmo tempo, as batidas de nosso coração para nossos intestinos, cujos movimentos são igualmente estranhos, relativamente isolados de nosso coração, ao mesmo tempo em que articulados com ele.

Corpo e eu (ou psiquismo, ou subjetividade, etc.) são palavras que ajudam a circundar certas experiências, que perduram juntas por certo tempo. No entanto, a simples atenção mais delicada e demorada a essas realidades evidencia sua natureza fragmentada, fugidia, acêntrica, de "agregados" de outras realidades igualmente fu- 
gidias e fragmentáveis (pensamentos, imagens, memórias, células, tecidos, átomos, energia). Como ressoa um antigo texto zen-budista: "a forma é vazio, o vazio é forma"15.

E, no entanto, no outro lado do problema, também a psicanálise, ainda que tenha testemunhado e reafirmado o descentramento do sujeito, a impossibilidade da identidade e da total auto-coerência, precisou afirmar a experiência de integração como um dos fundamentos da constituição subjetiva, assim como também afirma a existência de um "verdadeiro self"16 e da unidade entre corpo e sujeito (psico-soma), como vimos.

Mas, se corpo e sujeito não são entes ou totalidades fechadas, de que se trata o "verdadeiro self"? E em que sentido nossa singularidade subjetiva é corporal?

Para pensar essa questão, mais um relato de experiência talvez possa nos ajudar: o arquiteto Peter Zumthor, em seu discurso de aceitação do prêmio Pritzker de 2009, conta que não se reconheceu nos dois primeiros prédios que projetou, tendo visto neles a reprodução de discussões e conceitos com os quais havia entrado em contato, mas que não tinham a ver com o que ele "era" ou com o que ele desejava fazer como arquiteto. Depois de relatar essa experiência, ele diz o seguinte:

Então, o que é isso de ser eu mesmo? É interessante que nesses prédios, que me deram tanta dor de cabeça, dor no coração, havia coisas de que eu gostava, coisas que não tinham vindo de uma revista ou de uma discussão sobre a qual é possível conversar com alguém. Essas outras coisas, isto sou eu! O que é esse "eu"? É claro que eu não sei exatamente. Mas eu posso tentar explicar um pouco sobre o processo do que eu sinto quando isso acontece, quando eu tenho o sentimento "isto sou eu". Talvez aqueles de vocês que jogam tênis, vocês saibam. Você tem de se concentrar na bola. Se você começa a pensar só por um momento, "ah, meu amigo está olhando como eu jogo", então você está perdido, certo? Você tem de manter essa total concentração no que você quer fazer. Isto é uma coisa. A outra coisa é que você tem de estar solto [loose]. Agora, estou falando sobre mim. Devo dizer que eu tenho de estar solto. Eu vou ao lugar. Eu ouço o cliente. Eu ando, vagueio pelo espaço. Não estou indo fazer pesquisa.

Quando eu começo a fazer pesquisa, estou realmente mal. Isto eu sei de estudar. Nenhuma pesquisa. Você está só passeando, escutando, sentindo, deixando o lugar ressoar um pouco. E então, tudo de uma vez, as ideias vêm naturalmente. Eu não sei quando e onde. Eu acho isto um processo muito natural. Todo mundo todos vocês, todos nós - nós vivemos essa experiência. E o que eu descobri foi que quando eu tenho estes sentimentos, é como ser um menino de novo. Tudo de uma vez, eu penso que este sou eu quando tinha 10 ou 12 anos. Estou sonhando. Estou lá e algo vem até mim, mas não é, é claro, um sonhar ingênuo. Tudo o que é parte da minha biografia está lá. Mas não está lá como um produto de pesquisa ou um material de referências. Veio até mim, como parte de minha vida. Então isso vem de algum lugar - de minhas emoções, ou o que seja, meus sentimentos. Então, eu estou no mesmo lugar como no tempo em que eu experimentei a arquitetura como um menino, sem saber disso. Isto é o que eu amo. Estes começos,

\footnotetext{
15 Cf. Gonçalves, 2000, p. 67.

16 Conceito cunhado por Winnicott em referência à singularidade e à subjetivi-

dade (diferente da noção freudiana de "ego"), e em oposição a uma formação

defensiva que ele denomina de "falso self" (cf. Winnicott, 1983)
} 
estes momentos do começo

(Zumthor, 2009). ${ }^{17}$

O testemunho de Zumthor toca claramente no tipo de experiência que, de nosso ponto de vista, fez Winnicott distinguir entre falso e verdadeiro self. No relato do arquiteto, são precisamente enfocados vários aspectos que podemos destacar como características fundamentais da experiência de improvisação e do brincar - o valor do processo, o estado de repouso, a suspensão do olhar para si mesmo como um olhar de fora, a espera, a emergência do "gesto espontâneo". ${ }^{18}$

Sob esse ponto vista, o "verdadeiro self" aparece, acontece, no brincar e na experiência de criação, não como constituição de um ente dotado de uma identidade fixa, mas como uma forma particular de estar no mundo e com os outros, que pode atravessar o tempo na medida em que é sustentada por certa modalidade de encontro e por certa constância do ambiente.

Como Zumthor deixa claro, essa experiência de "isto sou eu!", é uma experiência corporal: acontece quando se está "inteiro" na ação (como no exemplo do jogo de tênis) - sem interferência do distanciamento da experiência gerado pela autocrítica, como uma operação do pensamento em que nos vemos como um objeto sobre o qual podemos fazer certo juízo - e quando há alguma liberdade, quando o sujeitocorpo está "solto" e pode vaguear.

Algo dessa experiência atravessa o tempo, como os traços de um rosto atravessam os diferentes corpos que constituem uma vida a cada instante, e, no entanto, ao mesmo tempo, essa experiência só pode seguir acontecendo na medida em que não fecha uma identidade à qual se apegar e à qual corresponder ativamente. É preciso deixar-se acontecer.

A dança baseada na improvisação e no contato oferece possibilidades valiosas e elementos concretos de sustentação para isso. Não é casual que a Improvisação de contato tenha começado com a experimentação da "pequena dança"19: quando nos pomos em pé e simplesmente ficamos ali, emerge um corpo vivo de pulsações e de relações cambiantes e sutis com a gravidade; emergem possibilidades de movimento e de gesto inesperadas, independentes da deliberação de um eu. Esse começo de toda improvisação, a "escuta" do que está acontecendo, a atenção ao corpo, à respiração, às pulsações, antes mesmo de que entre em jogo o outro corpo, já é um

\footnotetext{
17 "So what is this being myself? It is interesting that in these buildings, which gave me this headache, heart ache, there were things I liked, such as things that did not come from a magazine or from a discussion that I can talk about with somebody. Rather, this is me! What is this "me"? Of course, I don't know exactly. But I can try to explain a little about the process of what I feel when this happens, when I have the feeling "this is me." Maybe those of you who play tennis, you know. You have to concentrate on the ball. If you start to think just for a moment, "Oh, my friend is looking at how I play," then you are lost, right? You have to keep this total concentration on what you want to do. This is one thing. The other thing is you have to be loose. Now, I'm talking about myself. I should say I have to be loose. I go to the place. I listen to the client. I walk around. I hang around. I'm not going to do research.

When I start to do research, I'm really bad. This I know from studying. No research. You are just hanging out, listening, feeling, having the place resonate a little bit. And then all of a sudden, ideas come naturally. I don't know when and
}

where. I think this is a very natural process. Everybody_all of you, all of uswe experience this. And what I discovered was that when I have these feelings, it is like being a boy again. All of a sudden, I think this is me when I was 10 years or 12 years old. l'm dreaming. l'm there and something comes to me, but it's not, of course, naïve dreaming. Everything, which is part of my biography, is there. But it's not there as a research product or as reference material. It went into me, as part of my life. Then it comes out from somewhere-from my emotions or whatever, my feelings.

So, I'm at the same place as at the time when I experienced architecture as a boy without knowing it. This is what I love. These beginnings, these moments of the beginning." (Tradução livre feita pelo autor)

${ }^{18}$ Cf. Winnicott (1960/1983)

${ }^{19}$ Expressão cunhada por Steve Paxton para nomear o exercício de manterse em pé, o mais relaxado possível, observando os ajustes posturais reflexos constantes feitos involuntariamente pelo corpo. 
encontro. Nessa experiência o corpo é de fato uma forma de alteridade, na medida em que surpreende, estranha, tem dimensões, texturas, matizes pouco acessíveis na experiência cotidiana, muito além da imagem narcísica, da estruturação de um eu.

Por outro lado, esse corpo próprio que é um outro, no contato com mais um outro corpo, vai sendo devolvido a si mesmo. Começa a reconhecer seus limites e sua forma persistentes. Percebe o que muda a cada instante e o que persiste, acessa hábitos e caminhos privilegiados, surpreende-se tomando outros caminhos, o que reafirma os já habituais.

Por meio do contato com o outro, em movimento, podemos reconhecer o que já é conhecido e dado (ter um corpo com certa estrutura óssea, certo tamanho, certa tonicidade usual, ter duas pernas e dois braços, ter uma cabeça e um tronco, não ter olhos na nuca, etc.), e ao mesmo tempo tocar espaços de escolha e de criação. Como quando uma criança brinca com um objeto (transformando, por exemplo, um sapato em um carro, e uma colher em uma bruxa), na dança, o brincar acontece entre as características do 'objeto' e o horizonte de possibilidades que elas abrem (o sapato, por seu formato e solidez, por estar quase sempre no chão, por ter um dentro e um fora, tende a se prestar mais, na brincadeira, a ser um carro do que a ser um castelo, uma boneca ou uma toalha, ainda que essas possibilidades possam acontecer, dependendo do encontro singular do brincante com determinado sapato, de todo modo, é a partir das características dadas e reconhecidas do sapato que o "faz de conta" se desenrolará).

Jogamos com um corpo que não é absolutamente plástico como uma massinha de modelar, mas que se mostra, no movimento com o outro, sempre possível de nos surpreender. Nesse sentido, na experiência gerada pela improvisação em contato, o corpo pode ser ora um outro com quem brincamos, como pode ser o sujeito que brinca. Não há porque decidir peremptoriamente por um ou por outro. A lógica paradoxal do brincar, aqui discutida como paradigmática para se pensar a experiência estética, nos permite abordar as experiências de alteridade do próprio corpo sem passar pela submissão a representações hegemônicas totalizantes. É possível esperar um pouco e deixar que a brincadeira revele que corpo-outro é esse e como nos constituiremos a partir de cada encontro com certa faceta alteritária de nossa própria corporeidade.

\section{Referências}

BANES, Sally. Democracy's body: Judson Dance Theater: 1962-1964. Durham (EUA): Duke University Press, 1983.

BANES, Sally. Terpsichore in sneakers: post-modern dance. Middletown (EUA): Wesleyan University Press, 1987.

BENJAMIN, Walter. A doutrina das semelhanças. In: Obras escolhidas: Magia e técnica, arte e política. São Paulo: Brasiliense, 1994. (Originalmente publicado em 1933). 
DEJOURS, Christophe. Le corps entre biologie et psychanalyse. Paris: Payot, 1986.

DIAS, Elsa Oliveira. Incorporação e introjeção em Winnicott. Winnicott e-prints. V. 2, n. 2. São Paulo: Sociedade Brasileira de Psicanálise Winnicottiana, 2007.

FERNANDES, Maria Helena. Corpo. São Paulo: Casa do Psicólogo, 2003.

FOUCAULT, Michel. Vigiar e punir. Petrópolis: Vozes, 2009. (Originalmente publicado em 1975).

FREUD, Sigmund. Lo ominoso. In: Obras completas. Trad. José L. Etcheverry. Buenos Aires: Amorrortu, 1992 (3a ed.), v. 17. (Originalmente publicado em 1919).

GIL, José. Movimento total: o corpo e a dança. São Paulo: Iluminuras, 2004.

GONÇALVES, Ricardo Mario. (org.). Textos budistas e zen-budistas. São Paulo: Cultrix, 2000.

GREINER, Christine. O Corpo: pistas para estudos indisciplinares. São Paulo: Annablume, 2005.

LAUNAY, Isabelle. O dom do gesto. In: GREINER, Christine. \& AMORIM, Claudia. (orgs.). Leituras do corpo. São Paulo: Annablume, 2003.

LE BRETON, David. Adeus ao corpo: antropologia e sociedade. Campinas: Papirus, 2003.

LE BRETON, David. Antropología del cuerpo y modernidad. Buenos Aires: Nueva Visión, 1995.

LUZ, Rogério. O espaço potencial. In: LINS, Maria Ivone Accioly \& LUZ, Rogério. D. W. Winnicott: experiência clínica e experiência estética. Rio de Janeiro: Revinter, 1998.

MERLEAU-PONTY, Maurice. Signos. São Paulo: Martins Fontes, 1991.

NAFFAH NETO, Alfredo. Sobre a elaboração imaginativa das funções corporais: corpo e intersubjetividade na constituição do psiquismo. In: COELHO JR., Nelson Ernesto., SALEM, Pedro e KLATAU, Perla (orgs.). Dimensões da intersubjetividade. São Paulo: Escuta/Fapesp, 2012.

NOVACK, Cynthia Jean. Sharing the Dance: Contact Improvisation and American Culture. Madison (Wisconsin, EUA): The University of Wisconsin Press, 1990.

SAFRA, Gilberto. A face estética do self. São Paulo: Unimarco e Aparecida, SP: Ideias e Letras, 2005. 
SATN'ANNA. Denise Bernuzzi. Corpo e história. Cadernos de subjetividade. V. 5, n. 5. São Paulo: PUC-SP/EDUC, 1996.

SMITH, Nancy Stark. Setting our sights. In: SMITH, Nancy Stark e NELSON, Lisa. (orgs.). Contact Quarterly's Contact Improvisation Sourcebook. Northampton (MA, EUA): Contact Editions, 1997. (Artigo originalmente publicado em 1979).

SMITH, Nancy Stark. Back in time. In: SMITH, Nancy Stark e NELSON, Lisa. (org.). Contact Quarterly's Contact Improvisation Sourcebook. Northampton (MA, EUA): Contact Editions, 1997. (Artigo originalmente publicado em 1986).

SUQUET, Annie. Cenas - O corpo dançante: Um laboratório da percepção. In: COURTINE, Jean-Jacques. (org.). História do corpo. Vol. 3: As mutações do olhar. O século XX. Petrópolis: Vozes, 2008.

UNO, Kuniichi. Corpo-gênese ou tempo-catástrofe. Cadernos de Subjetividade. V. 12, N. 12. PUC-SP, 2010.

WINNICOTT, Donald Woods. Distorção do ego em termos de falso e verdadeiro self. In: O ambiente e os processos de maturação. Porto Alegre: Artmed, 1983. (Originalmente publicado em 1960).

WINNICOTT, Donald Woods. O Brincar e a realidade. Rio de Janeiro: Imago, 1975.

ZUMTHOR, Peter. Acceptance discourse. Prêmio Pritzker 2009. Disponível em: http://www.pritzkerprize.com/laureates/2009/ceremony_speech1.html

Recebido em: 15/05/2015 Aprovado em: 30/05/2015 